\title{
Surface guidance of stem cell behavior: chemically tailored co- presentation of integrin-binding peptides stimulates osteogenic differentiation in vitro and bone formation in vivo
}

Roberta Fraioli ${ }^{1,2}$, Khandmaa Dashnyam ${ }^{3,4}$, Joong-Hyun $\mathrm{Kim}^{3,4}$, Roman A Perez ${ }^{3,4}$, Hae-Won $\mathrm{Kim}^{3,4,5}$, Javier Gil ${ }^{1,2}$, Maria-Pau Ginebra ${ }^{1,2,6}$, José María Manero ${ }^{1,2^{*}}$, and Carlos Mas-Moruno ${ }^{1,2^{*}}$

${ }^{1}$ Biomaterials, Biomechanics and Tissue Engineering Group, Department of Materials Science and Metallurgical Engineering, Technical University of Catalonia (UPC), ETSEIB, Av. Diagonal 647, 08028, Barcelona, Spain

${ }^{2}$ Centre for Research in NanoEngineering (CRNE) - UPC, C/ Pascual i Vila 15, 08028, Barcelona, Spain

${ }^{3}$ Institute of Tissue Regeneration Engineering (ITREN), Dankook University, Cheonan, 330-714, Republic of Korea

4 Department of Nanobiomedical Science \& BK21 PLUS NBM Global Research Center for Regenerative Medicine, Dankook University, Cheonan, 330-714, Republic of Korea

${ }^{5}$ Department of Biomaterials Science, School of Dentistry, Dankook University, Cheonan, 330-714, Republic of Korea

${ }^{6}$ Institute for Bioengineering of Catalonia (IBEC), C/ Baldiri Reixac 10, 08028, Barcelona, Spain

${ }^{*}$ Corresponding Author(s):

e-mail: carles.mas.moruno@upc.edu

Telephone: +34934010814

Fax: +34 934016706

e-mail: jose.maria.manero@upc.edu

Telephone: +34934010714

Fax: +34 934016706 


\section{Abstract}

Surface modification stands out as a versatile technique to create instructive biomaterials that are able to actively direct stem cell fate. Chemical functionalization of titanium has been used in this work to stimulate the differentiation of human mesenchymal stem cells (hMSCs) into the osteoblastic lineage, by covalently anchoring a synthetic double-branched molecule (PTF) to the metal that allows a finely controlled presentation of peptidic motifs. In detail, the effect of the RGD adhesive peptide and its synergy motif PHSRN is studied, comparing a random distribution of the two peptides with the chemically-tailored disposition within the custom made synthetic platform, which mimics the interspacing between the motifs observed in fibronectin. Contact angle measurement and XPS analysis are used to prove the efficiency of functionalization. We demonstrate that, by rationally designing ligands, stem cell response can be efficiently guided towards the osteogenic phenotype: In vitro, PTF-functionalized surfaces support hMSCs adhesion, with higher cell area and formation of focal contacts, expression of the integrin receptor $\alpha 5 \beta 1$ and the osteogenic marker Runx2, and deposition a highly mineralized matrix, reaching values of mineralization comparable to fibronectin. Our strategy is also demonstrated to be efficient in promoting new bone growth in vivo in a rat calvarial defect. These results highlight the efficacy of chemical control over the presentation of bioactive peptides; such systems may be used to engineer bioactive surfaces with improved osseointegrative properties, or can be easily tuned to generate multi-functional coatings requiring a tailored disposition of the peptidic motifs.

Keywords: integrin-binding peptides, osseointegration, titanium, RGD-PHSRN, hMSCs 


\section{Introduction}

Several therapies for the treatment of injured bone tissue are currently established, yet recent findings on the natural healing processes of the organism suggest new routes for improvement. The role of stem cells in the restoration of damaged tissue has been fully recognized [1,2], and much effort is nowadays dedicated to the understanding of the underlying mechanisms [3], with a view to establishing novel clinical treatments [4,5]. Mesenchymal stem cells (MSCs) are nonhaematopoietic, heterogeneous pluripotent cells that are capable of differentiating into several mesodermal and non-mesodermal cell lineages [6]. As traumatic injury occurs, these progenitor cells are mobilized from their niche and recruited to the damaged tissue, in order to contribute to the reparative process [7]. Their contribution to the natural healing response of the body has been described to be via in situ differentiation into cells that directly replace the damaged tissue and paracrine action (or trophic activity [8]), which controls the injury-related inflammatory response. [9] Particular attention has been given to the engineering of biomaterials that control the commitment of MSCs to specific lineages, such as neuronal [10], chondrogenic [11], cardiac [12], and osteoblastic [13]. However, harnessing MSC fate remains a major challenge. Addressing such challenge would be of great significance in the orthopaedic and maxillofacial field, where the capacity to stimulate the osteogenic differentiation of MSC on the surface of clinically-relevant materials (e.g. on titanium and its alloys) [14], would translate into higher rates of implant osteointegration and improved long-term functionality. Surface modification strategies can be used for this purpose. As a matter of fact, variations of the surface stiffness [15], chemical composition [16,17], topography [18,19], and hydrophilicity [20] have been proven to influence MSC response.

Among chemistry-based strategies of surface functionalization, the anchoring of integrin-binding ligands is a particularly interesting solution to guide osteodifferentiation [21,22]. Integrins are a family of heterodimeric transmembrane receptors, constituted by two non-covalently bound $\alpha$ and $\beta$ subunits, that are responsible for the communication of signals from the extracellular matrix (ECM) to the nucleus, and vice versa [23]. Although, a complete view on how integrin ligands influence the response of progenitor cells has not been achieved yet, peptides derived from the ECM have been used to modulate cell fate. This is the case of the two integrin-binding motifs present in the cell attachment site of fibronectin (FN): the Arg-Gly-Asp (RGD) peptide [24], which interacts with several 
integrin subtypes [25], and the Pro-His-Ser-Arg-Asn (PHSRN) motif, whose synergic effect increases the affinity of RGD for the integrin receptor $\alpha 5 \beta 1$ [26]. This integrin receptor has been proved to be important in osteogenesis and thus its specific engagement opens promising prospects in bone regeneration [22,27-29]. Presentation of RGD and PHSRN sequences at the proper distance is crucial to preserve their synergic behavior [30,31]. The effect of these two ECM-derived motifs on cell adhesion has been studied in the literature [30,32-35], but their capacity to induce osteogenic differentiation of MSCs on metallic substrates has been only achieved by using engineered recombinant fragment of FN encompassing the whole cell attachment site of the protein [36-38]. Nonetheless, the limitations associated to the use of proteins urge the development of alternative synthetic approaches that mimic and retain their integrin-binding specificity but offer higher chemical control, safety and stability [39]. To mimic the 30-40 A distance that separates the motifs in FN [40,41] within a synthetic ligand, several linkers have been proposed, including polyglycine chains, $(\mathrm{Gly})_{6}[42,43]$ or $(\mathrm{Gly})_{13}$ [35], as well as (Ser-Gly) $)_{5}$ units [32]. In our study we use

a novel design based on a double-branched molecule (Figure 1), which uses 4 aminohexanoic acid (Ahx) molecules linked via a lysine (Lys) residue as spacer. When the branches adopt an open conformation, such spacer covers approximately the same distance as 12 Gly.[44] Hence, the aim of this study is to characterize the response of human MSCs (hMSCs) on Ti surfaces functionalized

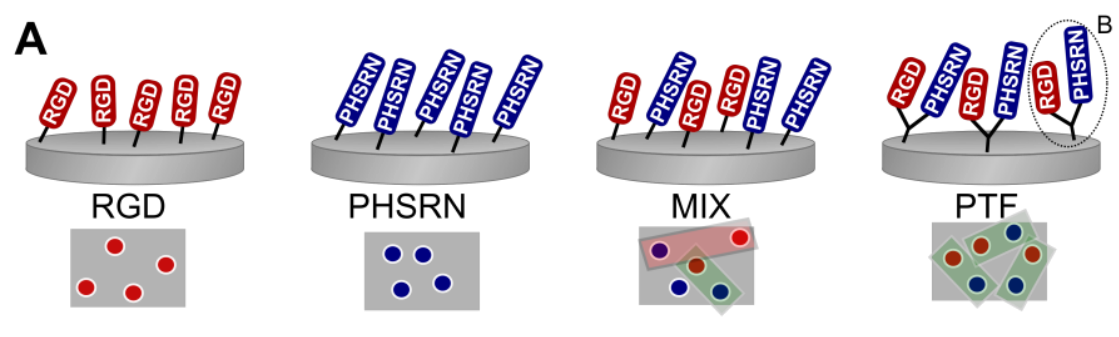

B
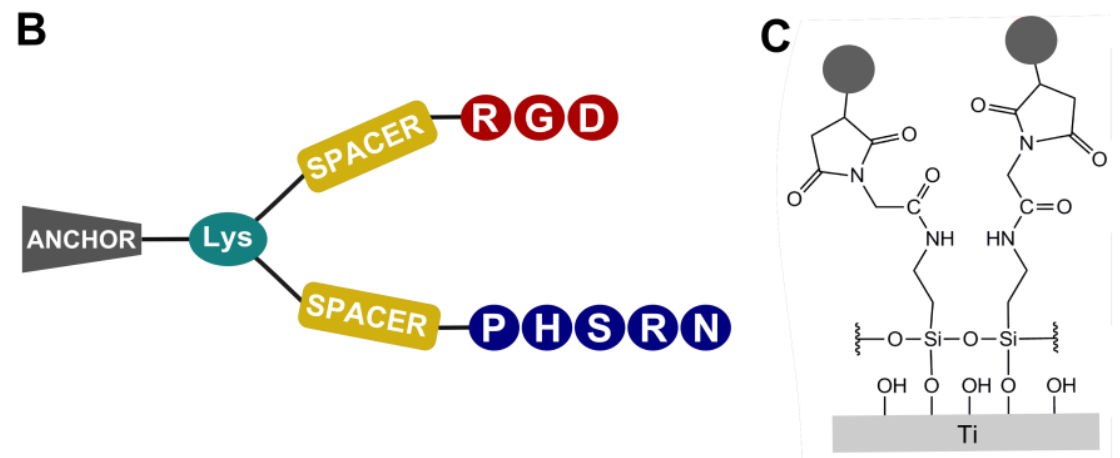

Figure 1 Schematic representation of the functionalized surfaces (A) and of the double-branched platform (B). Silanization of the Ti substrate is used to covalently graft the ligands (grey spots) (C). 
with a novel synthetic platform (PTF) [44], in which the RGD and PHSRN motifs are chemically inserted in a controlled fashion, and compare it with the presentation of the motifs alone or in a geometrically random distribution (Figure 1). To the best of our knowledge, the effect on hMSCs and the in vivo response due to such synthetic system of ligand presentation, which mimics the biological orientation and spacing of RGD and PHSRN sequences present in FN, has never been addressed before. To this end, we realized a straightforward three-step procedure to anchor the integrin-binding ligands to $\mathrm{Ti}$, and studied the effect on hMSCs behavior in terms of cell number, spreading, focal contacts, proliferation, gene expression and mineralization. The capacity of the PTF to promote bone formation in vivo was evaluated in a calvarial defect model in rats.

\section{Materials and methods}

\subsection{Functionalization of titanium surfaces}

\subsubsection{Synthesis of the bioactive molecules}

The platform (Ac-Arg-Gly-Asp-Ser-Ahx-Ahx)(Ac-Pro-His-Ser-Arg-Asn-Ahx-Ahx)-Lys- $\beta A$ la-Cys-NH ${ }_{2}$ (PTF) and the linear peptides MPA-Ahx-Ahx-Ahx-Arg-Gly-Asp-Ser-OH (RGD) and MPA-Ahx-AhxAhx-Pro-His-Ser-Arg-Asn- $\mathrm{NH}_{2}$ (PHSRN) (Ahx: aminohexanoic acid; MPA: 3-mercaptopropionic acid) were manually synthesized by solid-phase peptide synthesis methods following the Fmoc/tBu strategy and using 2-chlorotrityl chloride (CTC, $200 \mathrm{mg}, 1.0 \mathrm{mmol} / \mathrm{g}$ ) or Fmoc-Rink amide MBHA resin (200 $\mathrm{mg}, 0.45 \mathrm{mmol} / \mathrm{g}$ ) as solid supports, as recently reported [44]. Details on the chemical structure of each molecule are given in Figure S1 of the Supporting Information.

\subsubsection{Protocol of immobilization}

The covalent attachment of the biomolecules on the titanium (Ti) surfaces was done by silanization according to reported protocols [45,46] optimized in our laboratories [47] (Figures S1 B).

Ti disks (diameter: $1 \mathrm{~cm}$ ) were obtained by turning from a cylindrical bar of commercially pure (CP) grade 2 Ti (Technalloy S.A., Sant Cugat del Vallès, Spain), smoothed with SiC grinding papers (Neuertek S.A., Eibar and Beortek S.A.,Asua-Erandio, Spain), and polished with suspension of alumina particles ( $1 \mu \mathrm{m}$ and $0.05 \mu \mathrm{m}$ particle size, Buehler, Germany) on cotton clothes, until achieving smooth mirror-like surfaces. Polished disks were ultrasonically cleaned (by soaking in 
cyclohexane, isopropanol, Milli-Q (MQ) water, ethanol and acetone), and dried with nitrogen for storage. Surface passivation was carried out before silanization, by soaking disks in nitric acid (65 $\%$ v/v, Sigma-Aldrich, St. Louis, MO, USA) for $1 \mathrm{~h}$. Afterwards, disks were silanized in $2 \%(\mathrm{v} / \mathrm{v})$ APTES in anhydrous toluene (Sigma-Aldrich) at $70{ }^{\circ} \mathrm{C}$ for $1 \mathrm{~h}$ under nitrogen atmosphere under agitation, ultrasonically rinsed in toluene for $5 \mathrm{~min}, \mathrm{MQ}$ water, ethanol, and acetone. Curing of the silane layer was performed at $120{ }^{\circ} \mathrm{C}$ for $5 \mathrm{~min}$. The crosslinking agent $\mathrm{N}$-succinimidyl-3maleimidopropionate (SMP) (Alfa Aesar, Karlsruhe, Germany) was coupled straight after silanization by immersing disks in N,N-dimethylformamide (DMF, 7.5 M SMP in DMF, under agitation) for $1 \mathrm{~h}$ at room temperature (RT) and rinsing with DMF, distilled water, ethanol and acetone afterwards. Subsequently, a $100 \mu \mathrm{L}$ drop of a solution of the integrin-binding peptides $(100 \mu \mathrm{M}$ in PBS at $\mathrm{pH} 6.5)$, was deposited on the metallic surfaces overnight to covalently anchor the biomolecules to the Ti samples. Samples were coded according to the biofunctional molecule as follows: RGD, PHSRN, MIX (equimolar combination of RGD and PHSRN) and the platform (PTF) (Figure 1A). FN-coated disks (FN) $(50 \mu \mathrm{g} / \mathrm{mL}$ in PBS at $\mathrm{pH} 9.5)$, and nitric acid treated (CTRL) Ti disks were used as positive and negative controls for the biological studies, respectively. All samples were rinsed in either MQ water or PBS three times before performing the assays. The functionalization system is schematically represented in figure $1 \mathrm{C}$. In order to prevent unspecific cell attachment to the surface, prior to biological tests all samples were immersed in a solution of short polyethylene glycol (PEG) chains $\left(\mathrm{H}_{3} \mathrm{C}-(\mathrm{PEG})_{4}-\mathrm{SH}, 500 \mu \mathrm{M}\right.$, Thermo Scientific, Waltham, MA, USA ) for $1 \mathrm{~h}$ at RT. Thiolated PEG chains are expected to bind to unreacted maleimide groups of the crosslinker agent. Moreover, thiol groups of the polymeric chains can physisorb on Ti oxide $[44,48]$, capping the unreacted areas of the surface.

\subsection{Physicochemical characterization}

Static contact angle measurement (Contact Angle System OCA15 plus, DataPhysics, Filderstadt, Germany) and X-ray photoelectron spectroscopy (XPS) were used to characterize the physicochemical properties of Ti surfaces in each step of the functionalization process. MQ water and diiodomethane were chosen as wetting liquids. Contact angle values were obtained using Laplace-Young fitting with SCA 20 software (DataPhysics), and used to calculate the superficial 
energy with Young-Laplace and Owens-Wendt equations [49]. The system for the XPS analysis was equipped with a non-monochromatic $\mathrm{Mg}$ anode X50 source, operating at $150 \mathrm{~W}$ and a Phoibos 150 MCD-9 detector (SPECS Surface Nano Analysis system GmbH, Berlin, Germany). Detectorpass energy was fixed at $25 \mathrm{eV}$ with $0.1 \mathrm{eV}$ steps to record high resolution spectra at a pressure below $7.5 \times 10^{-9}$ mbar. Fitting and peak integration of spectra was done with Casa XPS software (Version 2.3.16, Casa Software Ltd., Teignmouth, UK). The C1s spectra were calibrated at 284.4 eV prior to analysis. Atomic percentages were calculated by subtracting a Shirley-type background, integrating the area under the peak and dividing by transmission, mean free path and sensitivity factors.

\subsection{Cell culture}

hMSCs (SCR 108, Merck Millipore) were cultured in Advanced Dulbecco's Modified Eagle's Medium (DMEM) supplemented with $10 \%$ (v/v) fetal bovine serum (FBS), $50 \mathrm{U} / \mathrm{mL}$ penicillin,50 $\mu \mathrm{g} / \mathrm{mL}$ streptomycin and $1 \%(\mathrm{w} / \mathrm{v})$ L-glutamine. Cells were maintained at $37^{\circ} \mathrm{C}$, in a humidified atmosphere containing $5 \%(\mathrm{v} / \mathrm{v}) \mathrm{CO}_{2}$, changing culture medium twice a week. For passaging, upon reaching $70 \%$ confluence, cells were detached by trypsin-EDTA and replated into a new flask. Osteogenic medium (OG-medium) was additionally supplemented with $10 \mathrm{mM} \beta$-glycerophosphate, $50 \mu \mathrm{g} / \mathrm{mL}$ ascorbic acid, and $100 \mathrm{nM}$ dexamethasone. Cells at passages between 1 and 4 were used to carry out experiments. All reagents were purchased from Sigma-Aldrich, unless otherwise noted.

\subsection{Cell adhesion and proliferation}

To evaluate the attachment of cells to the functionalized metallic surfaces, hMSCs were plated at $10^{4}$ cells $/ \mathrm{mL}$ and incubated at $37{ }^{\circ} \mathrm{C}$ and $5 \%(\mathrm{v} / \mathrm{v}) \mathrm{CO}_{2}$ containing atmosphere. After $6 \mathrm{~h}$ of incubation in serum-free medium, immunofluorescent staining of cell nuclei and actin fibers was performed to count attached cells. After removing non-adherent cells by gently washing samples with PBS, hMSCs were fixed with paraformaldehyde (PFA, 4\% w/v in PBS) for $20 \mathrm{~min}$, and permeabilized with $500 \mu \mathrm{L} /$ disk of $0.05 \%(w / v)$ Triton X-100 in PBS for 20 min. After blocking the surface with $1 \%$ BSA (w/v) in PBS for 30 min, actin fibers and nuclei were stained by incubating with rhodamine-conjugated phalloidin (1:300, in Triton $0.05 \%(w / v)$ in PBS) for $1 \mathrm{~h}$ and with 4',6diamidino-2-phenylindole (DAPI) (1:1000, in PBS-Glycine $20 \mathrm{mM})$ for 2 min at RT in the dark, 
respectively. Mouse anti-vinculin (1:100, in 1\% BSA (w/v), $1 \mathrm{~h})$ and Alexa 488 anti-mouse (1:2000 in Triton $0.05 \%(w / v)$ in PBS, $1 \mathrm{~h})$ were used to stain vinculin. Samples were rinsed three times with PBS-Glycine for $5 \mathrm{~min}$ between each step of the staining procedure. A fluorescence inverted microscope (AF7000, Leica, Germany) was used to examine Ti disks, and quantification of nuclei, cell projected areas and focal contacts was done with the Fiji/lmage-J package, either with the analyze particle plugin (nuclei) or manually (areas and focal contacts). To study proliferation of cells on the substrates, $6 \times 10^{3}$ cells $/ \mathrm{mL}$ were plated on samples in serum-free medium and incubated as previously explained. $4 \mathrm{~h}$ post seeding, medium was aspired and replaced with complete medium. After 3, 6, and 8 days of incubation, cell number was evaluated with the Alamar Blue assay (Invitrogen Life Technologies, Merelbeke, Belgium): briefly, Alamar Blue-containing medium (10\% $(\mathrm{v} / \mathrm{v}))$ was added for $1 \mathrm{~h}$, and fluorescence of the dye was quantified according to the manufacturer instructions with a multimode microplate reader (Infinite M200 PRO, Tecan GroupLtd., Männedorf, Switzerland). All reagents were purchased from Sigma-Aldrich, unless otherwise noted.

\subsection{Assessment of cell differentiation}

Gene expression of the integrin subunit a5 (ITGA5) and of the osteoblastic marker runt-related transcription factor 2 (RUNX2) was evaluated by RT-PCR analysis. $2 \times 10^{4}$ cells $/ \mathrm{ml}$ were plated on metallic disks and cultured for $24 \mathrm{~h}$ in basal medium. At harvest, cells were lysed and total RNA was extracted using RNeasy ${ }^{\circledR}$ Mini Kit (Qiagen, Hilden, Germany) according to manufacturer instructions. A NanoDrop ND-1000 spectrophotometer (Thermo Scientific, Waltham, MA, USA) was used to quantify total RNA. RNA (200 ng) was reverse transcripted to cDNA with QuantiTect Reverse Transcription Kit (Qiagen). A StepOnePlus Real-Time PCR System (Applied Biosystems, Foster City, CA, USA) with QuantiTect SYBR Green RT-PCR Kit (Qiagen) and gene-specific primers (Table 1) were used, doing a 5 min incubation at $95{ }^{\circ} \mathrm{C}$ and 40 amplification cycles (10 sec at $95{ }^{\circ} \mathrm{C}$ and $30 \mathrm{sec}$ at $60{ }^{\circ} \mathrm{C}$ ), followed by a melt curve. Melting curve analysis was done to prove specificity and gene expression was normalized to $\beta$-actin.

For mineralization assays, after seeding cells in the same conditions described for the proliferation assays, hMSCs were cultured with basal or osteogenic medium for 21 days, changing medium twice a week. After gently rising samples with PBS, adhered cells were fixed with PFA, as previously 
described. Afterwards, Ti disks were washed twice with $\mathrm{MQ}$ water and $500 \mu \mathrm{L} /$ well of $40 \mathrm{mM}$ Alizarin Red S (ARS) (pH 4.2) was added. Samples were incubated with the dye at RT for 20 min while gently shaking. Prior to microscopy visualization, excess dye was washed off using copious washings with $\mathrm{MQ}$ water. Stained surfaces were then examined under an Olympus BX51 microscope (Olympus Corporation, Japan). The area of the stained calcium deposits was quantified with the Fiji/lmage-J package. All reagents were purchased from Sigma-Aldrich, unless otherwise noted.

\begin{tabular}{ccc}
\hline Target gene & Forward sequence & Reverse sequence \\
\hline B-ACTIN & AGAGCTACGAGCTGCCTGAC & CGTGGATGCCACAGGACT \\
ITGA5 & GGGGGCTTCAACTTAGACG & CTCCCACCAGCACACTGAC \\
RUNX2 & CGGAATGCCTCTGCTGTTAT & TGGGGAGGATTTGTGAAGAC
\end{tabular}

Table 1 PCR primer sequences for integrin subunit $\alpha 5$ (ITGA5), runt-related transcription factor 2 (RUNX2) and $\beta$-actin.

\subsection{Protein adsorption assay}

Protein adsorption on $\mathrm{Ti}$ surfaces was tested by immersing the samples in fluorescein isothiocyanate-stained bovine serum albumin (FITC-BSA). Pierce ${ }^{\circledR}$ Antibody Labeling Kit (Thermo Scientific, USA) was used to label the protein, according to manufacturer's instructions. Briefly, BSA (Sigma Aldrich) was mixed with FITC in a phosphate-borate buffer and purified in a spin column to remove the non-reacted FITC. Then, samples were incubated with $150 \mu \mathrm{L}$ of FITC-BSA at a concentration of $100 \mu \mathrm{g} / \mathrm{mL}$ for $1 \mathrm{~h}$ in the darkness. After fixing with PFA, samples were examined under a Nikon E-600 fluorescence microscope (Nikon Corporation Instruments Company, USA). To quantify protein adsorption, five images were taken for each sample and the Fiji/lmage-J package was used to calculate pixel intensity.

\subsection{In vivo implantation}

The ability of the PTF to induce bone formation on the surface of Ti samples was assessed in vivo in a rat partial thickness calvarial model. The protocol of housing, care, and experimentation was approved by the Animal Care and Use Committee at Dankook University, Republic of Korea. Twelve 
11 week-old, 250-300 g healthy male Sprague-Dawley rats were used. Animals were acclimatized for 7 days before use and each rat was housed in a separate cage under temperature- and humidity-controlled environment, exposed to a $12 \mathrm{~h}$ light-dark cycle, and had free access to water and food. Custom-made rod-type $\mathrm{Ti}$ implants $(5.5 \mathrm{~mm}$ diameter, $5 \mathrm{~mm}$ long) were prepared following the same functionalization method as for the in vitro assays. After coating, samples were washed three times in sterile $\mathrm{MQ}$ water and sterilized by treatment with $70 \%$ ethanol for $30 \mathrm{~min}$. Implant placement was performed under general anesthesia using an intramuscular injection of a mixture of ketamine $(80 \mathrm{mg} / \mathrm{kg})$ and xylazine $(10 \mathrm{mg} / \mathrm{kg})$. The animals were randomly allocated to one of the two groups before implantation $(n=6): 1)$ Ti as a control group (CTRL) and 2) PTF-treated Ti as a study group (PTF). After shaving over the cranial lesion, the surgical site was scrubbed with iodine and $70 \%$ ethanol, and a linear skin incision was made. A full thickness flap was retracted and the calvarial bone was exposed. Two $5.5 \mathrm{~mm}$ diameter partial thickness calvarial bone defects were prepared in each rat on each side of the parietal bone under cooling conditions with sterile saline using a dental handpiece and a $5.5 \mathrm{~mm}$ diameter LS-Reamer (Neobiotech, Seoul, South Korea). The Ti samples were covered by 3D printed rigid polymer caps, and the cap and Ti constructs were secured to the calvarial bone using fixation screws via its anchoring rings (Figure S2). Rigid polymer caps (5.5 mm inner diameter and $5 \mathrm{~mm}$ height) were custom-made (Taulman 618 Nylon, Taulman 3D, Missouri, US) by 3D printing (NP-Mendel, Opencreators, South Korea). The subcutaneous

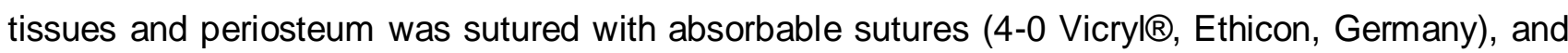
the skin was closed with non-absorbable suture material (4-0 Prolene, Ethicon, Germany). The animals were monitored daily for possible clinical signs of infection, inflammation, and any adverse reaction. After two and four weeks, the animals were euthanized by $\mathrm{CO}_{2}$ inhalation and the tissue part of the calvarium surrounding the cap was harvested and fixed in $10 \%$ neutral buffered formalin for 24 hours at RT.

\subsection{Histological preparations}

The cap and Ti were removed after fixation, and histological evaluations were done by classical methods. The fixed samples were subsequently decalcified in RapidCal ${ }^{\mathrm{TM}}$ solution (BBC Chemical Co., Stanwood, WA, USA) for 2 to 3 days. After decalcification, the samples were dehydrated in 
ascending grades of ethanol and embedded in paraffin. Five-micrometer coronal sections of the central area at the defect site were prepared and stained with hematoxylin and eosin $(\mathrm{HE})$ for the assessment of bone to $\mathrm{Ti}$ junction. Histological analysis was performed using a light microscope mounted Charge-Coupled Devices (CCD) camera (IX71, Olympus, Tokyo, Japan) at 200 magnification.

\subsection{Statistical analysis}

For the in vitro study, each condition was replicated in triplets in each experiment, which was at least repeated twice independently. Statistical significance was analyzed with ANOVA using Tukey's test for pair-wise comparison, setting $p<0.05$, unless otherwise specified (Minitab 16.2.2 Statistical Software, www.minitab.com, Minitab Inc.). Values reported in graphs are mean + standard deviation. 


\section{Results}

\subsection{Functionalization of Ti: evolution of physicochemical properties of the surface}

The sessile drop method was used to measure the contact angle of three $1 \mu \mathrm{L}$ drops of either water (Fig. 2) or diiodomethane. The nitric acid treatment $\left(\mathrm{HNO}_{3}\right)$ resulted in a significant decrease of water contact angle, compared to polished samples (P). In contrast, silanization with APTES increased this value. Anchoring of the peptidic ligands in all cases resulted in a significant increase in wettability. Diiodomethane contact angle was not significantly affected by the functionalization process (not shown).

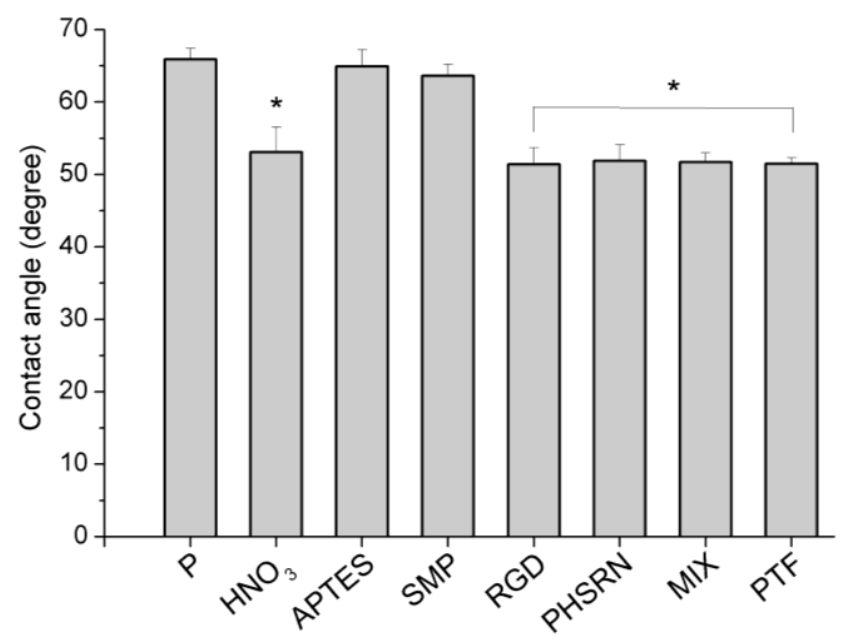

Figure 2 Water contact angle on Ti surfaces in each step of the functionalization process. * indicates statistical difference, vs. P, APTES and SMP $(p<0.05)$.

Surface chemical composition was analyzed via XPS analysis. Atomic percentages of the elements of interest (Ti, C, O, N, Si, and S) are presented in Fig. 3 A. Apart from all previously described conditions, PTF-coated Ti after an ultrasonication treatment in $\mathrm{MQ}$ water for $1 \mathrm{~h}$ was included to verify the stability of the ligand anchoring to the metal. Reaction yields can be estimated by using the atomic percentage data, as previously reported in literature $[45,46,50]$.

$$
\begin{aligned}
& R_{A P T E S \rightarrow S M P}=\left[(N / S i)_{S M P}-(N / S i)_{A P T E S}\right] /(N / S i)_{A P T E S} \\
& R_{S M P \rightarrow P T F}=\left\{\left[(N / S i)_{P T F}-(N / S i)_{S M P}\right] / \mathrm{m}\right\} /\left[(N / S i)_{S M P}-(N / S i)_{A P T E S}\right]
\end{aligned}
$$

where $(N / S i)_{i}$ is the measured atomic ration at the modification step and is the number of nitrogen atoms in the PTF molecule. The calculated reaction yields are 0.19 and 0.18 for reaction of 
the coupling of the crosslinker to APTES and anchoring of the PTF to the SMP molecule, respectively.

Analysis of the chemical composition of the uncoated $\mathrm{Ti}$ disks revealed the presence of three characteristics peaks: Ti $2 \mathrm{p}, \mathrm{O} 1 \mathrm{~s}$, and $\mathrm{C}$ 1s, the latter being associated to the presence of organic contaminants. $\mathrm{O}$ 1s spectrum presented a lower energy peak at binding energy (BE) $529.9 \mathrm{eV}$, attributed to the Ti dioxide, and a higher energy peak at $531.7 \mathrm{eV}$, resulting from the contribution of $\mathrm{Ti}$ hydroxide, physisorbed water and organic contaminants $\left(-\mathrm{C}=\mathrm{O},-\mathrm{C}-\mathrm{OH},-\mathrm{CO}_{2} \mathrm{H}\right)$, previously reported to appear between 531.7-532.5 eV [45,50]. Nitric acid passivation does not alter significantly the atomic percentage of the elements detected. However, deconvolution of the oxygen spectrum (Fig. 3 B) revealed a clear reduction of the higher energy peak, associated to C-bound oxygen groups. Silanization with APTES changed the elemental distribution of the surface: Ti and O were significantly reduced, while new signals from $\mathrm{N}$ (from $0.61 \%$ to $5.2 \%$, Fig. $3 \mathrm{~A}$ ) and Si appear. $\mathrm{N}$ 1s peak at $399.8 \mathrm{eV}$ (Fig. $3 \mathrm{~B}$ ) presented two components, which have been associated to protonated $\left(-\mathrm{NH}_{3}{ }^{+}\right)$and unprotonated $\left(-\mathrm{NH}_{2}\right)$ amino groups [46]. Si $2 p$ peak at $102.3 \mathrm{eV}$ (not shown) was also detected in this step, and its atomic percentage significantly increased from $0.14 \%$ to $7.2 \%$ (Fig. $3 \mathrm{~A}$ ). Moreover, silanization of the surface resulted in the modification of $\mathrm{O}$ is and $\mathrm{C} 1 \mathrm{~s}$ spectra. $\mathrm{O}$ 1s spectrum presents a new contribution at $532.0 \mathrm{eV}$, associated to -Si-O- bonds [46], and the peak of the $\mathrm{C}$ 1s spectrum at $285.8 \mathrm{eV}$, which can be ascribed to $-\mathrm{C}-\mathrm{N}$ bonds (previously reported at 286.4-286.5 eV [46,50]), increased its contribution (Fig. 3 B).

Upon addition of the crosslinking molecule, further increase in $\mathrm{C}$ and $\mathrm{N}$ atomic percentage was observed. The presence of new high energy bonds of the $\mathrm{C}$ atoms in the imide $(\mathrm{O}=\mathrm{C}-\mathrm{N}-\mathrm{C}=\mathrm{O}, \mathrm{BE}=$ $289 \mathrm{eV}$ [45]), from the maleimide group, and amide $(-\mathrm{NH}-\mathrm{C}=\mathrm{O}, \mathrm{BE}=288 \mathrm{eV}$ [45]), from the conversion of the amine group of APTES, functionalities contributed to the highest energy C $1 \mathrm{~s}$ peak growth $(\mathrm{BE}=288.0 \mathrm{eV})(\mathrm{Fig} .3 \mathrm{~B})$. The relative contribution of this peak increases from $5.7 \%$ in APTES samples to $13 \%$ after SMP coupling. The imide and amide groups also contribute to increase the peak of $\mathrm{N}$ 1s. However, deconvolution of imide, amide, protonated and unprotonated amines peaks is not possible, since they are associated to very similar binding energies and overlap in our spectra (previously reported at $400.6 \mathrm{eV}$ [45], $400.0 \mathrm{eV}$ [45], $401.2 \mathrm{eV}$ [44], $399.6 \mathrm{eV}$ [50], respectively). After coupling the PTF to the SMP molecule, sulphur, previously only present in 
traces, was detected, as shown in the inset in figure $3 \mathrm{~A}$. Further evidence of the presence of the synthetic ligand was given by the $\mathrm{O} 1 \mathrm{~s}$ and $\mathrm{N}$ 1s spectra deconvolutions: in the oxygen spectrum the highest energy peak, associated to amide groups, increased its contribution from $49.4 \%$ to 65.7\%; similarly, the nitrogen spectrum showed its predominant contribution at $399.7 \mathrm{eV}$, due to the numerous amide functionality of the PTF molecule. Neither atomic percentage nor spectrum deconvolutions are affected by the ultrasonication treatment in MQ water (condition PTF (S) in Fig 3). All the peaks of the analyzed spectra are reported in Table S1.
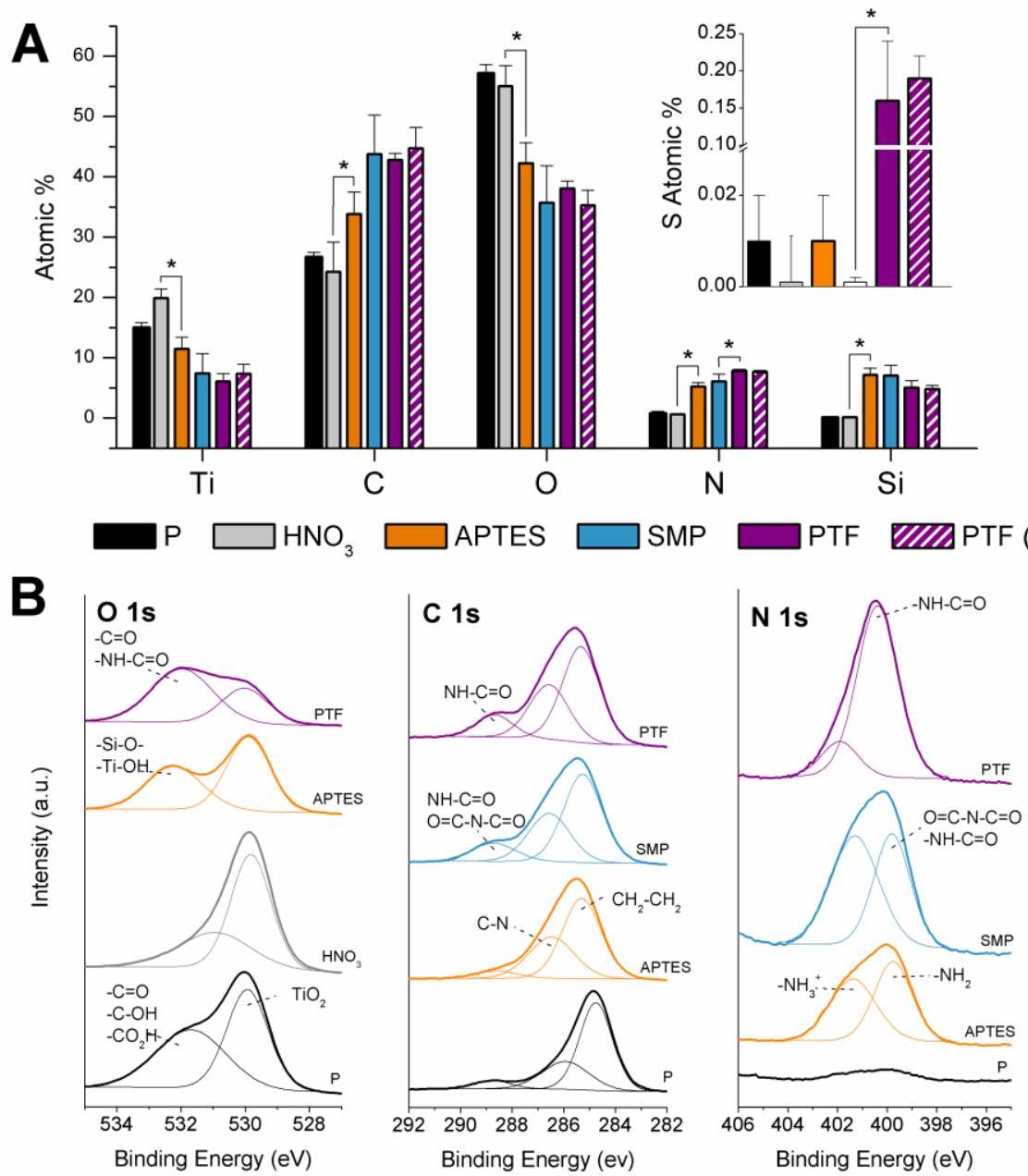

Figure 3 Atomic percentage of elements (A), high resolution spectra of oxygen, carbon and nitrogen (B) and chemical structure of the surface at each step of the functionalization process. *indicates statistical difference, compared to the previous step of the protocol $(p<0.05)$. 


\subsection{Protein adsorption assay}

Protein adsorption was performed to demonstrate that all conditions tested in vitro support the same protein adsorption. Compared to the untreated polished Ti disks $(\mathrm{P})$, on which higher protein adsorption is observed due to the lack of PEG chains, conditions tested in vitro, which have all been PEGylated to prevent unspecific interactions (uncoated, single peptide, and double-branched platform) support the same value of adsorption, which is statistically lower compared to P (Fig. S3).

\subsection{Attachment and proliferation of stem cells}

HMSCs were incubated on Ti disks in serum-free medium for $6 \mathrm{~h}$, and cell number evaluated by counting fluorescently labeled nuclei, as previously explained. No difference in the number of attached cells was observed among the surfaces presenting integrin-binding motifs (RGD, MIX, PTF and FN), which all presented a statistically higher cell adhesion, compared to CTRL and PHSRN surfaces (Fig. 4 A-B, p<0.01). Proliferation on the metallic substrates was evaluated after 3, 6, and 8 days of incubation (Fig. 4 C). On day 3 and 6, a significantly higher cell number is observed on all functionalized samples, compared to uncoated Ti $(p<0.05)$. No significant difference is observed among the different ligands immobilized. On day 8, both CTRL and PHSRN-coated Ti show lower cell number, compared to RGD-, MIX-, and PTF-coated disks $(p<0.05)$.
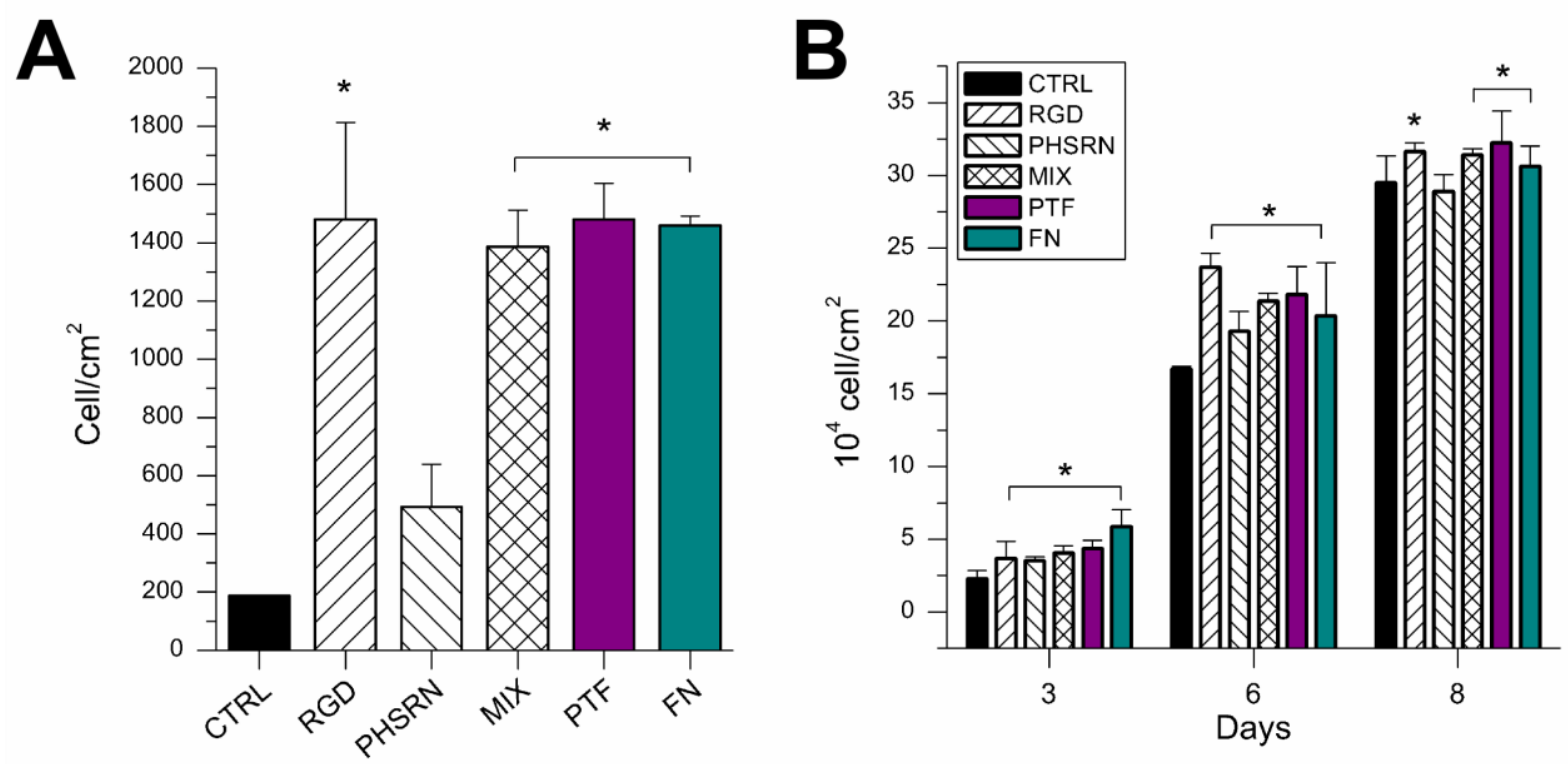

Figure 4 (A) Cell attachment after $6 \mathrm{~h}$ of incubation in serum-free medium. * indicates statistical difference relative to CTRL with $p<0.01$. (B) Cell proliferation after 3,6 and 8 days of incubation in basal medium. * indicates statistical difference vs. CTRL with $p<0.05$. 
F-actin was fluorescently labeled to visualize the extent of cell spreading on the surfaces. Cells on PHSRN stayed rather rounded or with little spreading, and poor organization of actin filaments was visible (Fig. 5 A). Well-defined actin fibers and higher cell spreading were visible on RGD, MIX, PTF and FN surfaces, compared to CTRL. PTF and FN surfaces promote the highest cell spreading, significantly higher than RGD- and MIX-coated surfaces (Fig. 5 B). Vinculin was also fluorescently labeled to visualize focal contacts on the functionalized surfaces (Fig. $5 \mathrm{C}$ ). No focal contacts were visible on uncoated and PHSRN-coated Ti (not shown), while RGD, MIX, PTF and FN surfaces presented clear vinculin spots. PTF, and to a higher extent FN, coatings allowed the formation of the most numerous focal contacts per cell, visible on the edges of actin filaments, both on the cell perimeter and throughout the area of cells. A trend toward larger focal contacts on FN and PTF (2.2 $\pm 0.6 \mu \mathrm{m})$, compared to RGD and MIX $(1.8 \pm 0.6 \mu \mathrm{m})$, was observed by quantifying adhesions length.

A
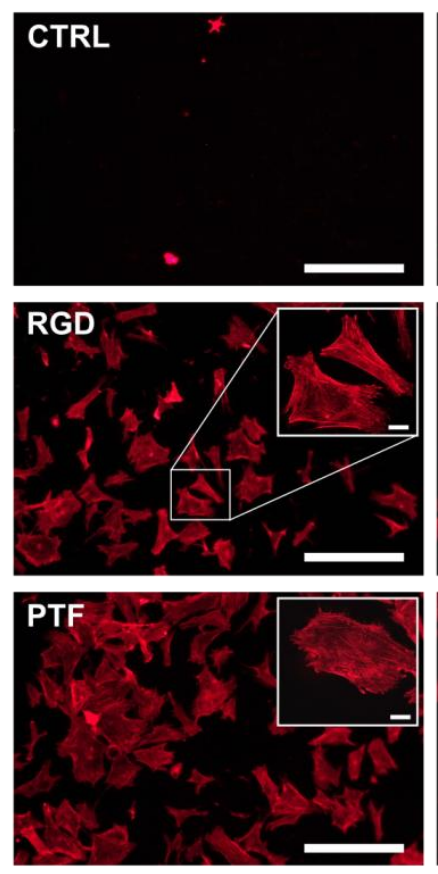
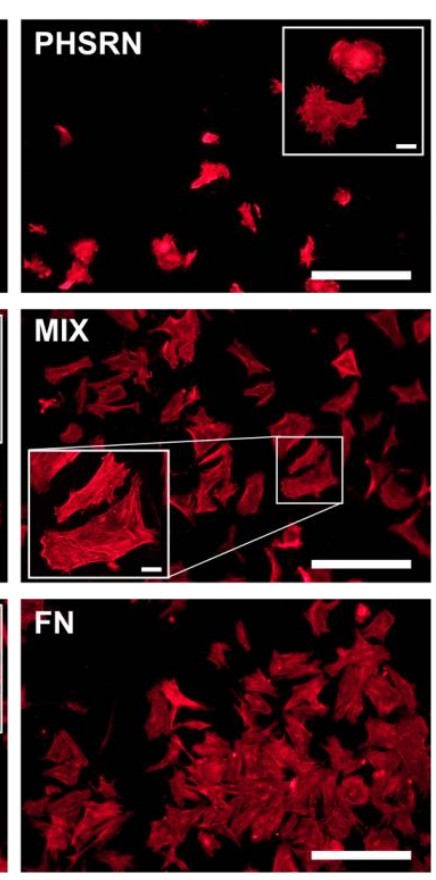

B

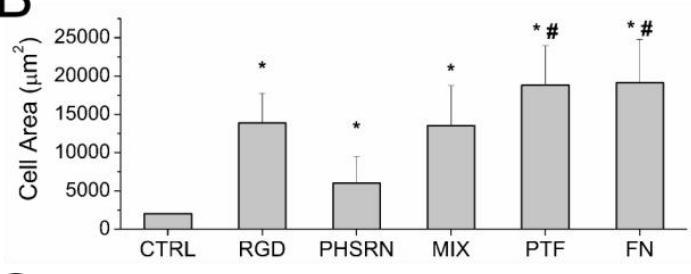

C
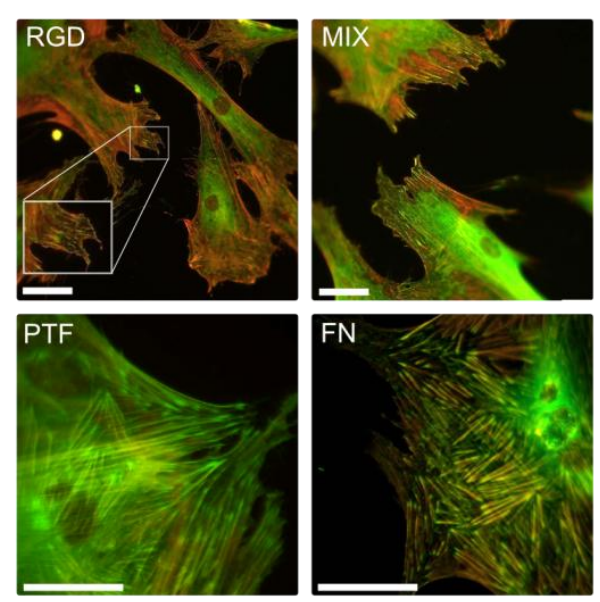

Figure 5 (A) F-actin immunostaining (scale bar $=500 \mu \mathrm{m}$, scale bar $=50 \mu \mathrm{m}$ in the insets), (B) projected cell area, *indicates statistical difference vs. CTRL with $\mathrm{p}<0.05$, \# indicates statistical difference vs. RGD and MIX with $p<0.05)$, and $(C)$ fluorescent staining of vinculin (scale bar $=50 \mu \mathrm{m}$ ) after $6 \mathrm{~h}$ of incubation in serum-free medium. 


\subsection{Gene expression analysis}

The expression of integrin $\alpha 5$ and of the osteogenic marker Runx2 was evaluated by RT-PCR after $24 \mathrm{~h}$ of incubation on the metallic surfaces in basal medium. mRNA expression was normalized to $\beta$-actin mRNA and analyzed both with ANOVA using Tukey's test for pairwise comparisons and with REST [51] (Fig. 6), according to the Pfaffl method [52]. Expression of a5 on the PTF-coated surface was upregulated compared to the PHSRN, MIX and FN $(p<0.05)$. Runx2 gene was also upregulated on the PTF, compared to CTRL $(p<0.0001)$, PHSRN $(p<0.0001)$ and MIX $(p<0.05)$ conditions.
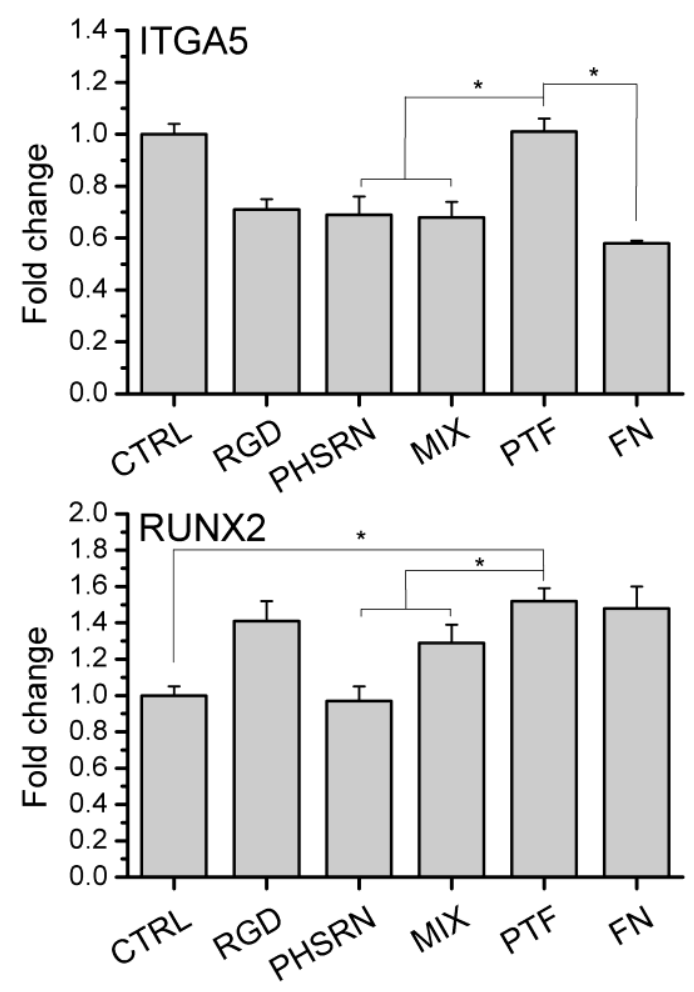

Figure 6 Expression of integrin a5 (ITGA5) and of the osteogenic marker Runx2 determined by RT-PCR for hMSCs cultured in basal medium. The mRNA expression levels were normalized to the expression of $\beta$-actin mRNA. *indicates statistical difference according to REST analysis (ITGA5: PTF vs. PHSRN $p<0.0001$, PTF vs. MIX and PTF vs. FN $p<0.05$. RUNX2: PTF vs. CTRL and PTF vs. PHSRN $p<0.0001$, PTF vs. MIX $p<0.05)$.

\subsection{Staining of calcium deposits}

In order to evaluate the extent of matrix mineralization on the functionalized substrates, staining of calcium deposits was done after 21 days of incubation in basal or OG medium. CTRL and PHSRN (not shown) samples presented the fewest and smallest deposits among conditions (Fig. 7). The anchoring of the RGD sequence on Ti promotes the formation of bigger calcium deposits (not 
shown), compared to CTRL. The presentation of the random distribution of linear RGD and PHSRN motifs (MIX, fig. 7) slightly increase mineralization, compared to RGD surface. PTF- and FN-coated surfaces supported the highest degree of mineralization: a higher number of calcium deposits were observed, and many of them were bigger compared to the MIX surface. Overall, quantification of the Alizarin Red S-positive areas revealed that mineralization is statistically higher on the PTF and FN in osteogenic medium, compared to CTRL (Figure S4).

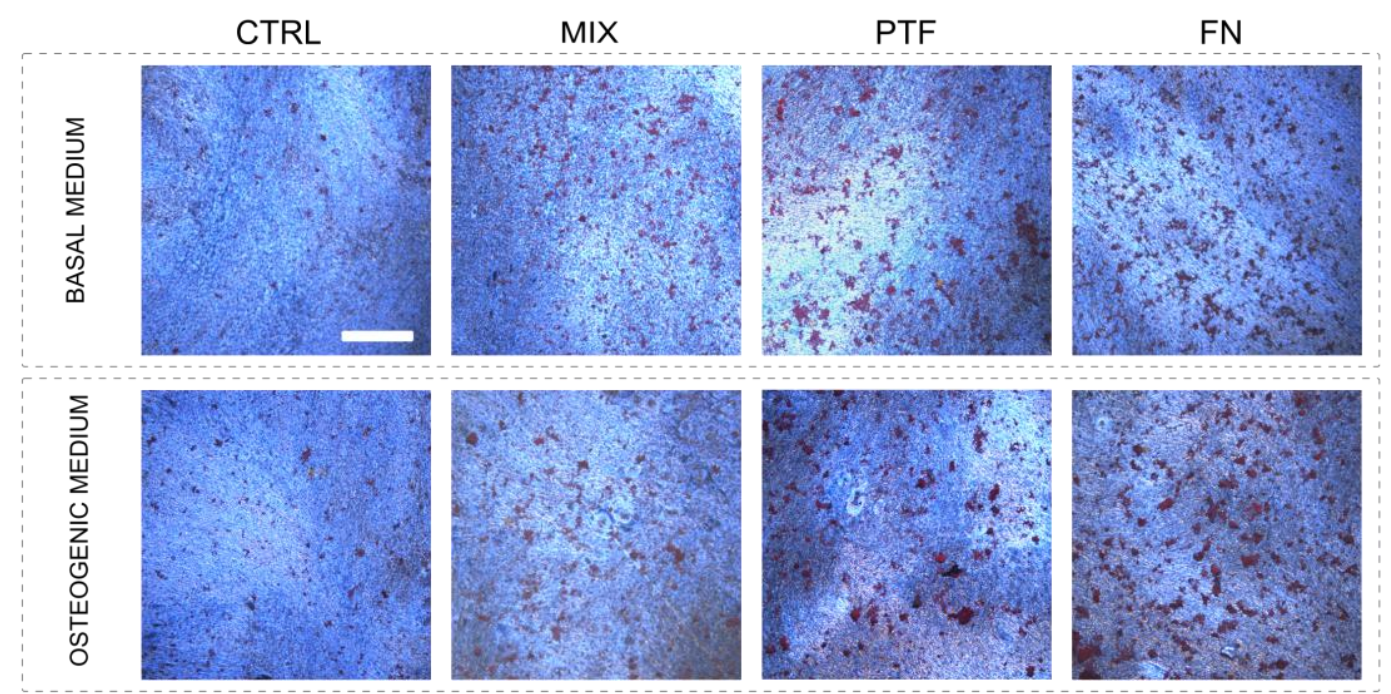

Figure 7 Alizarin Red S staining of calcium deposits after 21 days of incubation in basal or OG-medium. Scale bar $=500$ $\mu \mathrm{m}$. 


\subsection{In vivo implantation}

The ability of the PTF coating to stimulate bone regeneration in vivo was evaluated in a rat partial thickness calvaria defect model. Briefly, two calvaria defects were prepared in each rat, where Ti samples were inserted and secured in place with a plastic cap. After either 2 or 4 weeks implantation time, the animals were euthanized and the calvaria portion surrounding the implant was harvested for histological analysis.

All rats survived throughout the entire experiment, although two rats showed a local necrosis on the skin overlying the cap. The presence of the cap was associated with slight signs of inflammation although the histological results revealed that these focal responses did not affect the study results, and a remedial action was therefore not needed. After removing the cap, the macroscopic observation showed that the space between bone surface and Ti remained flat, and no significant differences were observed between groups. The PTF group showed a widespread thin layer of cortical bone developing both on top and bottom surfaces of the calvarial bone. Histological images showed new bone formation on the surface of the Ti disk, although with relevant histological differences between CTRL and PTF groups (Fig. 8 B). HE-stained histology images at high magnification (x200) revealed the peri-implant tissue with newly formed bone (arrows) above or below the host bone (dashed lines) showing woven features in all samples. Widespread bone formation was observed above the native bone level on the PTF treated surface, whereas the pristine $\mathrm{Ti}(\mathrm{CTRL})$ showed localized immature bone formation. PTF showed marked histological features of proliferative bone formation: osteoblasts were aligned on the surface of the bone, which seemed to be in a more advanced stage of bone remodeling. However, in the CTRL group, osteoblasts located adjacent to implant presented a disordered arrangement. Interestingly, new bone was not only generated on the surface of the defect, but also generated on the bottom surface

of the calvaria. Abundant connective tissue was generated between bone tissues on the Ti-PTF implant surfaces. 
A

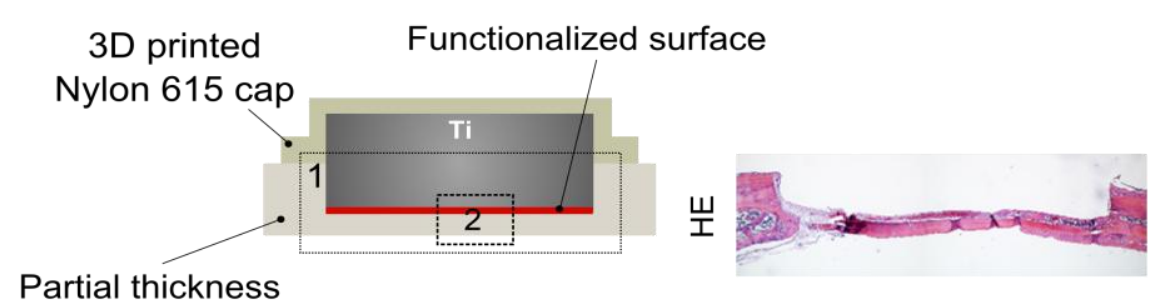
calvaria bone defect

B
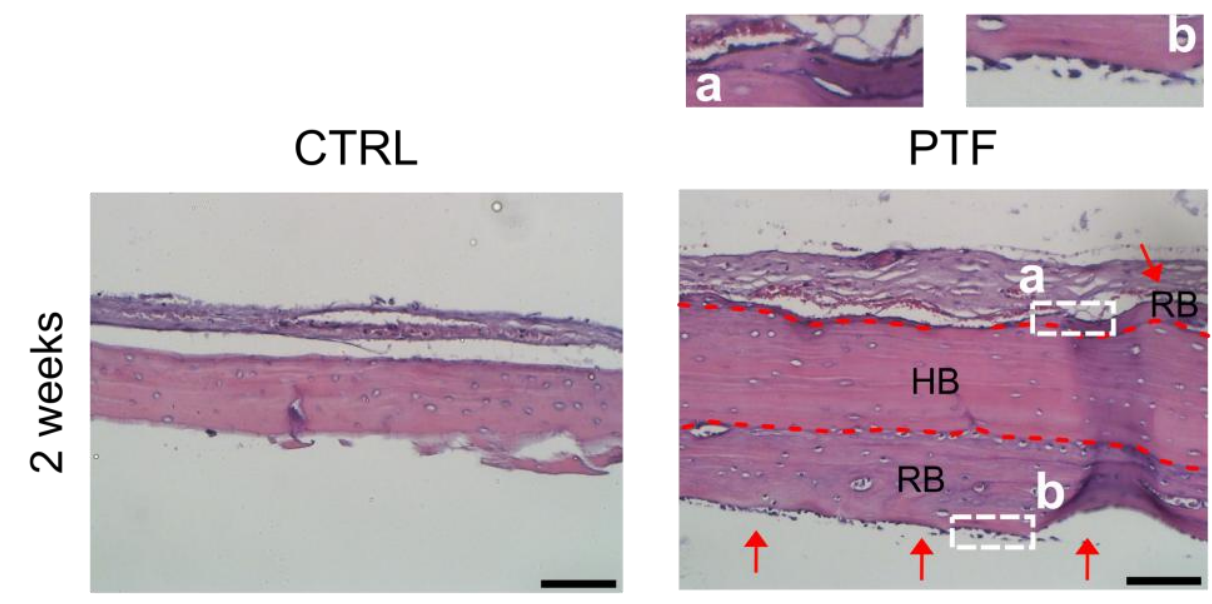

b
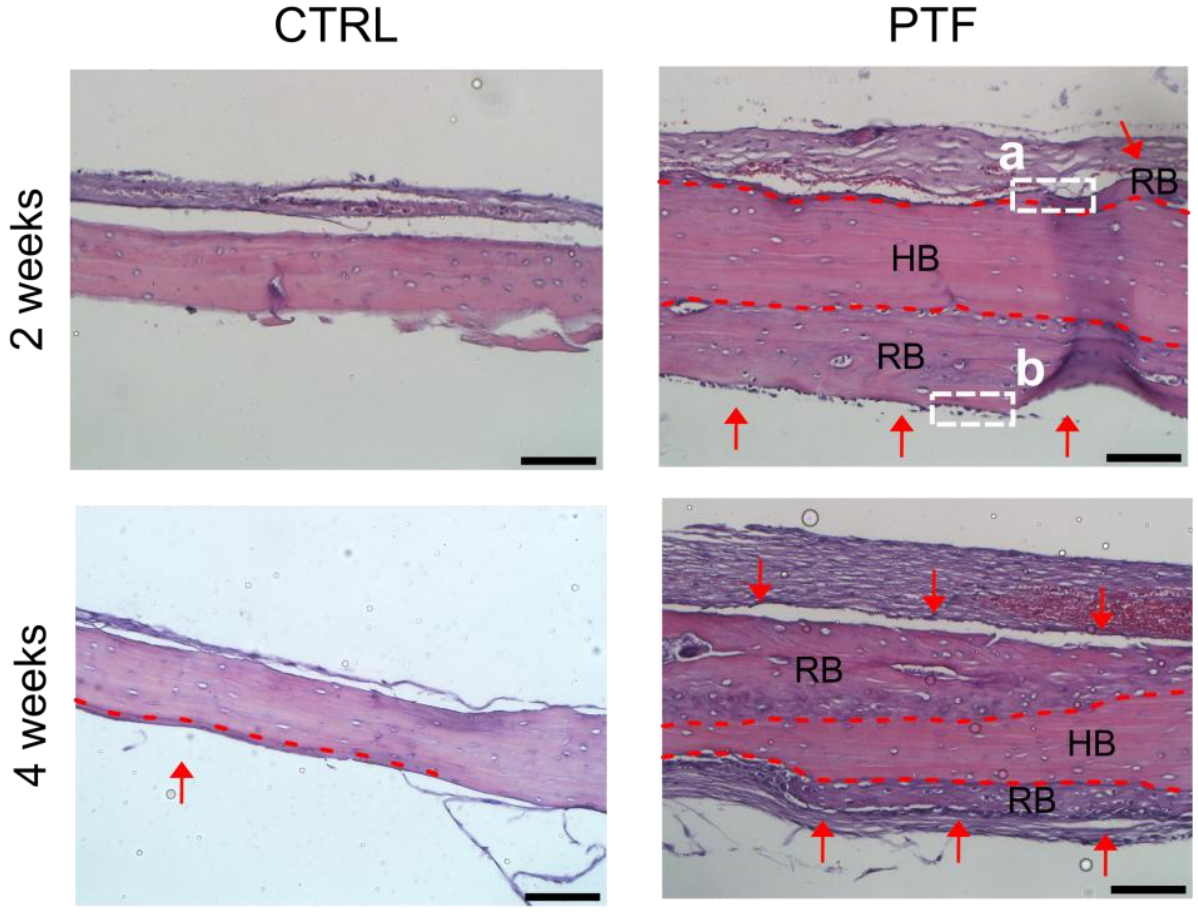

Figure 8 (A) Implantation scheme: 1 represents the analyzed area (light microscopic HE histology of section 1 on the right), and 2 the magnified areas represented in B. (B) x200 magnification (section 2) of the analyses areas (section 1). PTF groups showed widespread cortical reaction. The host bone (HB) is highlighted between the two red dot lines. New bone (red arrows) extends vertically onward the top and bottom of the calvarial bone surface, where osteoblasts are found to line mainly at the borders of the regenerated bone (RB), as shown in the insets (a) and (b). Scale bar $=100 \mu \mathrm{m}$. 


\section{Discussion}

The aim of this study is to develop a bioactive surface that guides the osteogenic differentiation of hMSCs by means of a chemically controlled presentation of integrin-binding ligands. In detail, the RGD and PHSRN sequences synergically bind integrin $\alpha 5 \beta 1$, which is known to be involved in several important events of bone biology [22,53-55], provided that the distance between the motifs mimics the one found in the protein $[31,32,35]$. For the synergic effect to take place, the spacing between the two sequences is crucial and it is often a difficult parameter to control $[32,35,42,43]$. To solve this issue, a double-branched platform (PTF) presenting the two motifs at a controlled distance is used to coat clinically-relevant Ti surfaces. The PTF structure is designed to separate RGD and PHSRN with a flexible spacer, consisting of $4 \mathrm{Ahx}$ and a branching Lys unit (Figure 1 and S1). We previously demonstrated that this synthetic ligand physisorbed on Ti promotes attachment and homogeneous spreading of osteoblast-like cells, compared to a random mix of RGD/PHSRN [44]. In this study covalent immobilization of the biomolecule is obtained via reaction of the thiol group (anchoring unit of the biomolecule) with the maleimide groups present in the organosilane layer though a Michael addition (Fig. S1 B). An analogous method is used to anchor single linear RGD or PHSRN alone or in a random mix for comparison. Due to the fact that the spacing between the biomolecules and the surface is known to affect the activity of the bioactive sequences $[48,56]$, all linear peptides were synthesized with spacer units (Ahx) to be presented at the same distance from the surface as the PTF (Fig. S1 A). The response of hMSCs to the custom synthesized platform is studied and the functionalization strategy is tested in an in vivo model.

\subsection{Immobilization of ligands on the metallic surface}

Physicochemical properties of the surface vary throughout the functionalization process, accordingly to the modifications applied. As shown in figure 2, nitric acid passivation reduces water contact angle. Most probably, this reduction is related to the efficient elimination of organic contaminants by the acidic treatment and a more homogenous layer of titanium dioxide. The same observation can be done by analysing the XPS data: the relative contribution of the highest energy peak of the $\mathrm{O}$ 1s spectrum, associated to organic contaminants, is highly reduced, whereas the low energy peak associated to titanium oxides increases (Fig. 3 B). Exposure of the oxide layer to adsorbed water 
molecules results in the formation of hydroxyl groups on the surface, which are necessary for the subsequent silanization step $[57,58]$. Therefore, passivation of the surfaces with nitric acid serves also as an effective activation treatment. After silanization, the wettability of the surface is significantly reduced, owing to the hydrophobic nature of the silanes. Chemical composition analysis by XPS also reveals significant changes in this step, confirming the efficiency of the modification process: the increases in both $\mathrm{Si}$ and $\mathrm{N}$ atomic percentages (Fig. $3 \mathrm{~A}$ ), the appearance of the -Si-Opeak and the increase in the relative contribution of the $-\mathrm{C}-\mathrm{N}$ - bonds peak (Fig. $3 \mathrm{~B}$ ) are typical indicators of successful silanization with APTES [45-47,50,57]. Addition of the crosslinking molecule is also confirmed by the XPS data, since a clear increase in the relative intensity of the $\mathrm{C}$ 1s peak associated to maleimide functionalities is visible, as previously observed in literature $[45,46]$ Moreover, N/Si ratio can be used to calculate reaction yield relative to the addition of SMP to APTES [45,59]: the calculated value $(0.19)$ indicates that about $20 \%$ APTES molecule react with the crosslinking agent, which is slightly lower than previously reported values for the same reaction step [45]. Upon anchoring of the peptides, contact angle is significantly reduced due to the hydrophilic character of the peptidic ligands. The wettability of all peptide-coated samples was statistically equal. These observations, apart from demonstrating the correct immobilization of the ligands on $\mathrm{Ti}$, also prove that biological effects cannot stem from differences in hydrophilicity among the modified surfaces. As a matter of fact, both wettability and surface chemistry are known to be regulators of cell responses $[17,20]$. Since in this study we aim at analyzing the effect of the chemistry of the surface, wettability must be kept constant among conditions. XPS analysis further confirms that the grafting of the peptides is effective. The new amide functionalities of the peptides increase the contribution of the $-\mathrm{N}-\mathrm{H}-\mathrm{C}=\mathrm{O}$-associated peaks in the $\mathrm{O} 1 \mathrm{~s}, \mathrm{C} 1 \mathrm{~s}$ and $\mathrm{N}$ 1s spectra (Fig. $3 \mathrm{~B}$ ). The calculated yield of the PTF reaction with the crosslinker is 0.19 , which is very close to values reported in literature for analogous peptidic sequences anchored to SMP $[45,46]$. Finally, the anchoring is proved stable to an ultrasonication treatment of $1 \mathrm{~h}$, since neither change in atomic percentages nor modification of the high resolution spectra is observed by XPS analysis (Fig. $3 \mathrm{~A}$ ). 


\subsection{HMSCs response in vitro}

Data collected from the in vitro assays carried out highlight that some aspects of cell response on functionalized $\mathrm{Ti}$ are more ligand-dependent than others. The analysis of short-term attachment of stem cells in serum-free conditions reveals that the presence of integrin-binding peptides on the surface promotes significantly higher cell adhesion in the first $6 \mathrm{~h}$ of incubation, compared to nonfunctionalized Ti (Fig. 4 A, B). Very few cells adhere on both the uncoated Ti and the PHSRNcoated surface. A large number of works already demonstrated that PHSRN alone does not bind cell surface receptors, unless synergically acting with the RGD sequence $[26,31,33,35,44,60-62]$. Interestingly, no difference in cell number is observed among the RGD, MIX, PTF and FN surfaces, probably due to the high density of ligands obtained under our coating conditions [63]. The linear RGD sequence is known to bind at least nine integrin subtypes when presented alone [64], and has higher affinity for $\alpha 5 \beta 1$ receptor when co-presented with the PHSRN at the proper distance (as in PTF) [65,66], while FN is known to bind several integrin and non-integrin receptors [67]. MIX surface, which presents the two motifs randomly spaced, also has a potentially high affinity for several integrin subtypes. Hence, results of the adhesion assays suggest that short-time attachment to the peptide-coated surface of this study may not depend upon a specific integrin subtype. The same observation has been reported in several studies with other cell types: For instance, endothelial cells seeded on functionalized PEG hydrogels showed a similar attachment to both RGD or an RGD/PHSRN combination [62]; similarly, no difference in the number of adherent fibroblasts was observed among polymer brushes coated with either RGD or RGD/PHSRN [61]. Moreover, murine osteoblasts have been shown to proliferate with the same efficiency on RGD or a mixture of the two peptides after 3 and 5 days, respectively [34]. Similarly, in our study cell growth on Ti is significantly increased when the peptidic ligands are attached to the metallic surface but no clear difference is observed among the bioactive RGD-containing molecules, which all promote proliferation of hMSCs to the same extent at all time points (Fig. 4 C). Despite no differences in cell number or proliferation are highlighted, the analysis of the projected cell area reveals that cells on the RGD and MIX surfaces spread less than on the PTF surface (Fig. 5 B). We observed the same effect in a previous study: osteoblast-like cells more efficiently spread on the surface presenting the RGD/PHSRN motifs at controlled distance (PTF condition) [44]. The observation that cell spreading 
is promoted on PTF and FN confirms that the receptor $\alpha 5 \beta 1$, for which both ligands have high affinity, is important in enhancing cell spreading [26] and highlight the capacity of the PTF to present the two motifs at a proper distance. The influence of the geometrical distribution of RGD/PHSRN on spreading was observed in other studies: For example, Ochsenhirt et al. reported that cells spread more when an equimolar mixture of RGD and PHSRN was distributed on the surface [33]. However, this effect was only noticeable at certain concentrations that might allow the distance between the motifs to be similar to the one encountered in FN. It should also be noted that the majority of cells presents a marked polygonal shape, and very few spindle-shaped cells are visible. Since the morphology transition from spindle-shape to a spread shape has been associated to the differentiation into osteoblastic cells, this is an indication of commitment of stem cells into the osteoblastic lineage $[68,69]$.

The adhesive performance of the coated Ti surfaces was also analyzed in terms of focal contact formation, by staining the protein vinculin (Fig. $5 \mathrm{C}$ ), which is one of the cytoplasmic proteins forming the focal contact complex. After $6 \mathrm{~h}$ of incubation in serum-free conditions, fluorescently labelled vinculin spots are already visible on RGD, MIX, PTF and FN surfaces, indicating the formation of focal contacts with the substrate. The absence of vinculin spots in the CTRL and PHSRN conditions confirms the poor quality of attachment on these surfaces. Moreover, the presence of more intense and larger focal contacts on PTF, compared to RGD and MIX, could suggest that focal adhesion-mediated signaling is a possible mediator of the effect of the biomolecule on hMSCs. Larger focal adhesions have been associated to increased cytoskeletal tension, which in turn promotes osteogenesis of stem cells $[68,70]$.

Regarding gene expression analysis, the upregulation of a5 integrin, compared to all functionalized surfaces, confirms that the configuration of the RGD and PHSRN within the PTF molecule is efficient in supporting the synergy between these motifs in binding integrin $\alpha 5 \beta 1$, in absence of osteogenic supplements (Fig. 6), which are known to upregulate the expression of this subunit [27]. Moreover, in order to analyze the commitment of stem cells to the osteoblastic lineage, the expression of Runx2 is quantified (Fig. 6). This transcription factor, essential in the process of osteogenesis [71], has also been shown to be upregulated by integrin a5 [27]. In agreement with some previous studies [27], the expression level of the osteoblastic marker Runx2 is also 
upregulated on the PTF, compared to the uncoated Ti disk. Interestingly, despite the lower expression level of the a5 subunit on the RGD surface, the transcription factor is equally expressed on the RGD- and on the PTF-coated Ti disks. Similarly, on FN the integrin subunit a5 is downregulated compared to PTF; however, despite the low expression of this receptor, cells express high Runx2 level on FN after $24 \mathrm{~h}$ of incubation. This is likely due to the promiscuity of the full length protein, which binds several integrin subtypes and is involved in many signaling events that might foster the expression of this transcription factor. Gene analysis has been complemented by the analysis of the mineralization of the matrix (Fig. 7), which is a late marker of differentiation into the osteoblastic lineage. Calcium deposition follows a trend similar to the one observed for Runx2 expression: almost no calcium deposits are observed on CTRL and PHSRN surfaces, while RGD, MIX and PTF all show mineralization. These results are not unexpected: the transcription factor Runx2 is known to promote osteogenic differentiation by regulating the transcription of osteocalcin, which is associated to mineralization [71]. Thus, surfaces that present high Runx2 expression are expected to foster matrix mineralization. Nonetheless, the difference among these three surfaces is in this case more pronounced: the surface coated with the properly spaced RGD and PHSRN sequences (PTF) promotes the formation of the highest number and biggest calcium deposits among the peptidic ligands, reaching the same or higher mineralization than the FN-coated Ti.

Taken together, in vitro results demonstrate that the chemical presentation of co-localized RGD/PHSRN ligands in a geometrically controlled manner within our PTF is a feasible approach to support hMSCs adhesion on $\mathrm{Ti}$ and direct their commitment to the osteogenic phenotype. In particular, the synthetic PTF significantly enhances the adhesion, spreading, focal adhesion formation, and proliferation of hMSCs on these substrates. Furthermore, this approach upregulates the expression of $\alpha 5 \beta 1$ and Runx2, and fosters the formation of a highly mineralized matrix on the metallic substrate at a longer timescale. The biological effects exhibited by this synthetic ligand are comparable to those obtained by the native protein $\mathrm{FN}$, and outperform the presentation of the RGD motif alone or a random distribution of RGD/PHSRN ligands, thereby highlighting the feasibility and potential of this strategy of surface functionalization. 


\subsection{Bone growth in vivo}

To validate the functionality of our approach, Ti implants were functionalized with the PTF and their capacity to foster bone growth in vivo analyzed in a rat calvarial partial defect model. Although further studies with different models would be necessary to study newly generated bone functions, this rat calvarial model soundly informs about the capacity of the modified surface to stimulate early bone tissue growth.

In all group samples, the newly formed bone was still undergoing maturation, but some remarkable differences in histological parameters were observed: Osseointegration was positively affected by the PTF, accelerating bone repair compared to control uncoated Ti implants. Furthermore, increased cortical bone reactions were observed on PTF-treated surfaces, with new bone growing both along the upper and lower surfaces of the calvarial bone. New bone growth on the lower surface of the bone (non-functionalized surface) could respond to a PTF-mediated paracrine osteogenic effect on undifferentiated MSCs present in the dura mater, thus stimulating new bone growing underneath the defect. As previously reported in literature, the dura has powerful osteoinductive effects [72-74]. As a matter of fact, dura mater stem cells isolated from rat show excellent osteogenic differentiation, expressing several osteogenic markers and producing highly mineralized matrix [75]. As our in vivo study was carried out at 2 and 4 weeks, a period in which the bone formation is still early stage, it is possible to suggest an enhancing effect of the PTF coating on bone formation at early time points. Despite this positive outcome, fibrous tissue was also observed on top of the regenerated bone, which could potentially decrease the stability of the implanted material. This aspect needs to be taken into account in further studied. Nonetheless, enhanced bone formation at such early implantation periods would improve provide better outcomes, especially in clinical settings where the quality of bone is compromised.

\section{Conclusions}

This work explores the possibility of guiding cell fate in vitro and fostering in vivo osteointegration of a clinically-relevant material such as $\mathrm{Ti}$, by generating a controlled disposition of two synergic peptidic sequences, namely RGD and PHSRN. Our custom synthesized molecule (PTF) is designed so that the distance between the sequences mimics the one found in the integrin-binding site of $\mathrm{FN}$. 
This straightforward control of motifs disposition is demonstrated to positively influence the adhesion and osteogenic differentiation of hMSCs, which in turn translates into higher rates of bone formation in vivo. The positive biological outcomes observed in vitro and in vivo in this study are of relevance. Whereas synthetic RGD peptides have been widely used to produce bioactive materials, with excellent results at the in vitro level, their performance in clinically relevant scenarios has been rather modest, when not disappointing. This has raised debate on their role as coating molecules, despite their numerous advantages over full length proteins. Our work demonstrates that synthetic peptide ligands can be combined in a chemically defined fashion to overcome their limitations, i.e. the absence of synergistic domains within their sequence or their often-poor receptor activity/selectivity. We expect that the combinations of other bioactive motifs will expand the use of this platform to a wider range of biomaterials and applications that require a controlled disposition of peptidic motifs.

\section{Acknowledgements}

The authors thank the Spanish Government for financial support through Project No. MAT201567183-R (MINECO-FEDER), co-funded by the European Union through European Regional Development Funds. R.F. and C.M.-M thank the Government of Catalonia for financial support through a pre-doctoral and post-doctoral fellowship, respectively. C.M.-M also thanks the People Programme (Marie Curie Actions) of the European Union's Seventh Framework Programme (FP7PEOPLE-2012-CIG, REA Grant Agreement No. 321985) for funding this project. Partial financial supports from Korea government are also acknowledged (grant no. 2009-0093829 \& 2015032163). Dr. M. Dominguez (CRNE, UPC) is acknowledged for conducting XPS measurements and Mrs. C. Lorrain for technical support with the mineralization studies. 


\section{References}

[1] Prockop DJ, Gregory CA, Spees JL. One strategy for cell and gene therapy: harnessing the power of adult stem cells to repair tissues. Proc Natl Acad Sci U S A 2003;100 Suppl :1191723. doi:10.1073/pnas.1834138100.

[2] Caplan A. Adult mesenchymal stem cells for tissue engineering versus regenerative medicine. J Cell Physiol 2007:341-7. doi:10.1002/JCP.

[3] Walters NJ, Gentleman E. Evolving insights in cell-matrix interactions: Elucidating how nonsoluble properties of the extracellular niche direct stem cell fate. Acta Biomater 2015;11C:316. doi:10.1016/j.actbio.2014.09.038.

[4] Chen W, Shao Y, Li X, Zhao G, Fu J. Nanotopographical surfaces for stem cell fate control: Engineering mechanobiology from the bottom. Nano Today 2014;9:759-84.

[5] Sjöström T, McNamara LE, Meek RMD, Dalby MJ, Su B. 2D and 3D nanopatterning of titanium for enhancing osteoinduction of stem cells at implant surfaces. Adv Healthc Mater 2013;2:1285-93. doi:10.1002/adhm.201200353.

[6] Chamberlain G, Fox J, Ashton B, Middleton J. Concise review: mesenchymal stem cells: their phenotype, differentiation capacity, immunological features, and potential for homing. Stem Cells 2007;25:2739-49. doi:10.1634/stemcells.2007-0197.

[7] Fong ELS, Chan CK, Goodman SB. Stem cell homing in musculoskeletal injury. Biomaterials 2011;32:395-409. doi:10.1016/j.biomaterials.2010.08.101.

[8] Caplan AI, Dennis JE. Mesenchymal stem cells as trophic mediators. J Cell Biochem 2006;98:1076-84. doi:10.1002/jcb.20886.

[9] Fox JM, Chamberlain G, Ashton BA, Middleton J. Recent advances into the understanding of mesenchymal stem cell trafficking. Br J Haematol 2007;137:491-502. doi:10.1111/j.13652141.2007.06610.x.

[10] Thrivikraman G, Madras G, Basu B. Intermittent electrical stimuli for guidance of human mesenchymal stem cell lineage commitment towards neural-like cells on electroconductive substrates. Biomaterials 2014;35:6219-35. doi:10.1016/j.biomaterials.2014.04.018.

[11] Kim IL, Khetan S, Baker BM, Chen CS, Burdick JA. Fibrous hyaluronic acid hydrogels that direct MSC chondrogenesis through mechanical and adhesive cues. Biomaterials 2013;34:5571-80. doi:10.1016/j.biomaterials.2013.04.004.

[12] Cristallini C, Cibrario Rocchietti E, Accomasso L, Folino A, Gallina C, Muratori L, Pagliaro P, Rastaldo R, Raimondo S, Saviozzi S, Sprio AE, Gagliardi M, Barbani N, Giachino C. The effect of bioartificial constructs that mimic myocardial structure and biomechanical properties on stem cell commitment towards cardiac lineage. Biomaterials 2014;35:92-104. doi:10.1016/j.biomaterials.2013.09.058.

[13] Viswanathan P, Ondeck MG, Chirasatitsin S, Ngamkham K, Reilly GC, Engler AJ, Battaglia G. 3D surface topology guides stem cell adhesion and differentiation. Biomaterials 2015;52:140-7.

[14] Geetha M, Singh AK, Asokamani R, Gogia AK. Ti based biomaterials, the ultimate choice for orthopaedic implants - A review. Prog Mater Sci 2009;54:397-425. doi:10.1016/j.pmatsci.2008.06.004.

[15] Engler AJ, Sen S, Sweeney HL, Discher DE. Matrix elasticity directs stem cell lineage specification. Cell 2006;126:677-89. doi:10.1016/j.cell.2006.06.044.

[16] Olivares-Navarrete R, Rodil SE, Hyzy SL, Dunn GR, Almaguer-Flores A, Schwartz Z, Boyan BD. Role of integrin subunits in mesenchymal stem cell differentiation and osteoblast maturation on graphitic carbon-coated microstructured surfaces. Biomaterials 2015;51:69-79. doi:10.1016/j.biomaterials.2015.01.035.

[17] Benoit DSW, Schwartz MP, Durney AR, Anseth KS. Small functional groups for controlled differentiation of hydrogel-encapsulated human mesenchymal stem cells. Nat Mater 2008;7:816-23. doi:10.1038/nmat2269.

[18] Dalby MJ, Gadegaard N, Oreffo ROC. Harnessing nanotopography and integrin-matrix 
interactions to influence stem cell fate. Nat Mater 2014;13:558-69. doi:10.1038/nmat3980.

[19] Oh S, Brammer KS, Li YSJ, Teng D, Engler AJ, Chien S, Jin S. Stem cell fate dictated solely by altered nanotube dimension. Proc Natl Acad Sci U S A 2009;106:2130-5.

doi:10.1073/pnas.0813200106.

[20] Hwa J, Wasilewski CE, Almodovar N, Olivares-navarrete R, Boyan BD, Tannenbaum R, Schwartz Z. The responses to surface wettability gradients induced by chitosan nano films on microtextured titanium mediated by specific integrin receptors. Biomaterials 2012;33:738693. doi:10.1016/j.biomaterials.2012.06.066.

[21] Kilian KA, Mrksich M. Directing Stem Cell Fate by Controlling the Affinity and Density of Ligand-Receptor Interactions at the Biomaterials Interface. Angew Chemie 2012;124:4975-9. doi:10.1002/ange.201108746.

[22] Martino MM, Mochizuki M, Rothenfluh DA, Rempel SA, Hubbell JA, Barker TH. Controlling integrin specificity and stem cell differentiation in 2D and 3D environments through regulation of fibronectin domain stability. Biomaterials 2009;30:1089-97. doi:10.1016/j.biomaterials.2008.10.047.

[23] Hynes RO. Integrins: bidirectional, allosteric signaling machines. Cell 2002;110:673-87.

[24] Pierschbacher MD, Ruoslahti E. Cell attachment activity of fibronectin can be duplicated by small synthetic fragments of the molecule. Nature 1984;309:30-3. doi:10.1007/s13398-0140173-7.2.

[25] Shekaran A, García AJ. Extracellular matrix-mimetic adhesive biomaterials for bone repair. J Biomed Mater Res A 2011;96:261-72. doi:10.1002/jbm.a.32979.

[26] Aota S, Nomizu M, Yamada KM. The short amino acid sequence Pro-His-Ser-Arg-Asn in human fibronectin enhances cell-adhesive function. J Biol Chem 1994;269:24756-61.

[27] Hamidouche Z, Fromigué O, Ringe J, Häupl T, Vaudin P, Pagès J-C, Srouji S, Livne E, Marie PJ. Priming integrin alpha5 promotes human mesenchymal stromal cell osteoblast differentiation and osteogenesis. Proc Natl Acad Sci U S A 2009;106:18587-91. doi:10.1073/pnas.0812334106.

[28] Keselowsky B, Wang L, Schwarts Z, Garcia AJ, Boyan BD. Integrin a5 controls osteoblastic proliferation and differentiation responses to titanium substrates presenting different roughness characteristics in a roughness independent. J Biomed Mater Res Part A 2007;80:700-10. doi:10.1002/jbm.a.

[29] Seger R, Krebs EG. The MAPK signaling cascade. FASEB J 1995;9:726-35.

[30] Kao WJ, Lee D, Schense JC, Hubbell JA. Fibronectin modulates macrophage adhesion and FBGC formation: the role of RGD, PHSRN, and PRRARV domains. J Biomed Mater Res 2001;55:79-88.

[31] Grant RP, Spitzfaden C, Altroff H, Campbell ID, Mardon HJ. Structural Requirements for Biological Activity of the Ninth and Tenth FIII Domains of Human Fibronectin. J Biol Chem 1997;272:6159-66. doi:10.1074/jbc.272.10.6159.

[32] Mardilovich A, Craig JA, McCammon MQ, Garg A, Kokkoli E. Design of a novel fibronectin-mimetic peptide-amphiphile for functionalized biomaterials. Langmuir 2006;22:3259-64. doi:10.1021/la052756n.

[33] Ochsenhirt SE, Kokkoli E, McCarthy JB, Tirrell M. Effect of RGD secondary structure and the synergy site PHSRN on cell adhesion, spreading and specific integrin engagement. Biomaterials 2006;27:3863-74. doi:10.1016/j.biomaterials.2005.12.012.

[34] Chen X, Sevilla P, Aparicio C. Surface biofunctionalization by covalent co-immobilization of oligopeptides. Colloids Surf B Biointerfaces 2013;107C:189-97. doi:10.1016/j.colsurfb.2013.02.005.

[35] Benoit DSW, Anseth KS. The effect on osteoblast function of colocalized RGD and PHSRN epitopes on PEG surfaces. Biomaterials 2005;26:5209-20. doi:10.1016/j.biomaterials.2005.01.045.

[36] Petrie TA, Raynor JE, Reyes CD, Burns KL, Collard DM, García AJ. The effect of integrinspecific bioactive coatings on tissue healing and implant osseointegration. Biomaterials 
2008;29:2849-57. doi:10.1016/j.biomaterials.2008.03.036.

[37] Agarwal R, González-García C, Torstrick B, Guldberg RE, Salmerón-Sánchez M, García AJ. Simple coating with fibronectin fragment enhances stainless steel screw osseointegration in healthy and osteoporotic rats. Biomaterials 2015;63:137-45.

doi:10.1016/j.biomaterials.2015.06.025.

[38] Herranz-Diez C, Mas-Moruno C, Neubauer S, Kessler H, Gil FJ, Pegueroles M, Manero JM, Guillem-Marti J. Tuning Mesenchymal Stem Cell Response onto Titanium-NiobiumHafnium Alloy by Recombinant Fibronectin Fragments. ACS Appl Mater Interfaces 2016;8:2517-25. doi:10.1021/acsami.5b09576.

[39] Williams DF. The role of short synthetic adhesion peptides in regenerative medicine; the debate. Biomaterials 2011;32:4195-7. doi:10.1016/j.biomaterials.2011.02.025.

[40] Leahy DJ, Aukhil I, Erickson HP. 2.0 A crystal structure of a four-domain segment of human fibronectin encompassing the RGD loop and synergy region. Cell 1996;84:155-64.

[41] Johansson S, Svineng G, Wennerberg K, Armulik A, Lohikangas L. Fibronectin-integrin interactions. Front Biosci 1997;2:d126-46.

[42] Kim T, Jang J, Lee Y, Ryu I. Design and biological activity of synthetic oligopeptides with Pro-His-Ser-Arg-Asn (PHSRN) and Arg-Gly-Asp (RGD) motifs for human osteoblast-like cell (MG-63) adhesion. Biotechnol ... 2002:2029-33.

[43] Kao WJ, Lee D. In vivo modulation of host response and macrophage behavior by polymer networks grafted with fibronectin-derived biomimetic oligopeptides: the role of RGD and PHSRN domains. Biomaterials 2001;22:2901-9.

[44] Mas-Moruno C, Fraioli R, Albericio F, Manero JM, Gil FJ. Novel peptide-based platform for the dual presentation of biologically active peptide motifs on biomaterials. ACS Appl Mater Interfaces 2014;6:6525-36. doi:10.1021/am5001213.

[45] Xiao SJ, Textor M, Spencer ND, Wieland M, Keller B, Sigrist H. Immobilization of the celladhesive peptide Arg-Gly-Asp-Cys (RGDC) on titanium surfaces by covalent chemical attachment. J Mater Sci Mater Med 1997;8:867-72.

[46] Xiao S-J, Textor M, Spencer ND. Covalent Attachment of Cell-Adhesive, ( Arg-Gly-Asp ) Containing Peptides to Titanium Surfaces. Langmuir 1998;14:5507-16.

[47] Fraioli R, Rechenmacher F, Neubauer S, Manero JM, Gil J, Kessler H, Mas-Moruno C. Mimicking bone extracellular matrix: Integrin-binding peptidomimetics enhance osteoblastlike cells adhesion, proliferation, and differentiation on titanium. Colloids Surfaces B Biointerfaces 2015;128:191-200. doi:10.1016/j.colsurfb.2014.12.057.

[48] Mas-Moruno C, Dorfner PM, Manzenrieder F, Neubauer S, Reuning U, Burgkart R, Kessler $\mathrm{H}$. Behavior of primary human osteoblasts on trimmed and sandblasted Ti6Al4V surfaces functionalized with integrin $\alpha v \beta 3$-selective cyclic RGD peptides. J Biomed Mater Res A 2013;101:87-97. doi:10.1002/jbm.a.34303.

[49] Owens DK, Wendt RC. Estimation of the surface free energy of polymers. J Appl Polym Sci 1969;13:1741-7.

[50] Dettin M, Herath T, Gambaretto R, Iucci G, Battocchio C, Bagno A, Ghezzo F, Di Bello C, Polzonetti G, Di Silvio L. Assessment of novel chemical strategies for covalent attachment of adhesive peptides to rough titanium surfaces: XPS analysis and biological evaluation. $\mathbf{J}$ Biomed Mater Res A 2009;91:463-79. doi:10.1002/jbm.a.32222.

[51] Pfaffl MW, Horgan GW, Dempfle L. Relative expression software tool (REST) for groupwise comparison and statistical analysis of relative expression results in real-time PCR. Nucleic Acids Res 2002;30:e36. doi:10.1093/nar/30.9.e36.

[52] Pfaffl MW. A new mathematical model for relative quantification in real-time RT-PCR. Nucleic Acids Res 2001;29:2002-7. doi:10.1093/nar/29.9.e45.

[53] Shekaran A, Shoemaker JT, Kavanaugh TE, Lin AS, LaPlaca MC, Fan Y, Guldberg RE, García AJ. The effect of conditional inactivation of beta 1 integrins using twist 2 Cre, Osterix Cre and osteocalcin Cre lines on skeletal phenotype. Bone 2014;68C:131-41. doi:10.1016/j.bone.2014.08.008. 
[54] Hamidouche Z, Fromigué O, Ringe J, Häupl T, Marie PJ. Crosstalks between integrin alpha 5 and IGF2/IGFBP2 signalling trigger human bone marrow-derived mesenchymal stromal osteogenic differentiation. BMC Cell Biol 2010;11:44. doi:10.1186/1471-2121-11-44.

[55] Fromigué O, Brun J, Marty C, Da Nascimento S, Sonnet P, Marie PJ. Peptide-based activation of alpha5 integrin for promoting osteogenesis. J Cell Biochem 2012;113:3029-38. doi:10.1002/jcb.24181.

[56] Rechenmacher F, Neubauer S, Mas-Moruno C, Dorfner PM, Polleux J, Guasch J, Conings B, Boyen H-G, Bochen A, Sobahi TR, Burgkart R, Spatz JP, Fässler R, Kessler H. A molecular toolkit for the functionalization of titanium-based biomaterials that selectively control integrin-mediated cell adhesion. Chem - A Eur J 2013;19:9218-23. doi:10.1002/chem.201301478.

[57] Mas-Moruno C, Garrido B, Rodriguez D, Ruperez E, Gil FJ. Biofunctionalization strategies on tantalum-based materials for osseointegrative applications. J Mater Sci Mater Med 2015;26:1-12. doi:10.1007/s10856-015-5445-z.

[58] Hanawa T. A comprehensive review of techniques for biofunctionalization of titanium. J Periodontal Implant Sci 2011;41:263-72. doi:10.5051/jpis.2011.41.6.263.

[59] Dettin M, Bagno A, Gambaretto R, Iucci G, Conconi MT, Tuccitto N, Menti AM, Grandi C, Di Bello C, Licciardello A, Polzonetti G. Covalent surface modification of titanium oxide with different adhesive peptides: surface characterization and osteoblast-like cell adhesion. J Biomed Mater Res A 2009;90:35-45. doi:10.1002/jbm.a.32064.

[60] Danen EHJ, Aota SI, Van Kraats AA, Yamada KM, Ruiter DJ, Van Muijen GNP. Requirement for the synergy site for cell adhesion to fibronectin depends on the activation state of integrin $\alpha 5 \beta 1$. J Biol Chem 1995;270:21612-8. doi:10.1074/jbc.270.37.21612.

[61] Desseaux S, Klok H. Fibroblast adhesion on ECM-derived peptide modified poly(2hydroxyethyl methacrylate) brushes: Ligand co-presentation and 3D-localization. Biomaterials 2015;44:24-35.

[62] Fittkau MH, Zilla P, Bezuidenhout D, Lutolf MP, Human P, Hubbell JA, Davies N. The selective modulation of endothelial cell mobility on RGD peptide containing surfaces by YIGSR peptides. Biomaterials 2005;26:167-74. doi:10.1016/j.biomaterials.2004.02.012.

[63] Rezania A, Johnson R, Lefkow A, Healy K. Bioactivation of metal oxide surfaces. 1. Surface characterization and cell response. Langmuir 1999;15:6931-9.

[64] Hersel U, Dahmen C, Kessler H. RGD modified polymers: biomaterials for stimulated cell adhesion and beyond. Biomaterials 2003;24:4385-415. doi:10.1016/S0142-9612(03)00343-0.

[65] García AJ, Schwarzbauer JE, Boettiger D. Distinct activation states of alpha5beta1 integrin show differential binding to RGD and synergy domains of fibronectin. Biochemistry 2002;41:9063-9.

[66] Huebsch N, Arany PR, Mao AS, Shvartsman D, Ali OA, Bencherif SA, Rivera-Feliciano J, Mooney DJ. Harnessing traction-mediated manipulation of the cell/matrix interface to control stem-cell fate. Nat Mater 2010;9:518-26. doi:10.1038/nmat2732.

[67] Pankov R, Yamada KM. Fibronectin at a glance. J Cell Sci 2002;115:3861-3. doi:10.1242/jcs.00059.

[68] McBeath R, Pirone DM, Nelson CM, Bhadriraju K, Chen CS. Cell shape, cytoskeletal tension, and RhoA regulate stem cell lineage commitment. Dev Cell 2004;6:483-95. doi:10.1016/S1534-5807(04)00075-9.

[69] Zhang D, Kilian KA. The effect of mesenchymal stem cell shape on the maintenance of multipotency. Biomaterials 2013;34:3962-9. doi:10.1016/j.biomaterials.2013.02.029.

[70] Kilian KA, Bugarija B, Lahn BT, Mrksich M. Geometric cues for directing the differentiation of mesenchymal stem cells. Proc Natl Acad Sci U S A 2010;107:4872-7. doi:10.1073/pnas.0903269107.

[71] Marom R, Shur I, Solomon R, Benayahu D. Characterization of adhesion and differentiation markers of osteogenic marrow stromal cells. J Cell Physiol 2005;202:41-8. doi:10.1002/jcp.20109. 
[72] Levi B, Nelson ER, Li S, James AW, Hyun JS, Montoro DT, Lee M, Glotzbach JP, Commons GW, Longaker MT. Dura mater stimulates human adipose-derived stromal cells to undergo bone formation in mouse calvarial defects. Stem Cells 2011;29:1241-55. doi:10.1002/stem.670.

[73] Gosain AK, Santoro TD, Song L-S, Capel CC, Sudhakar P V, Matloub HS. Osteogenesis in calvarial defects: contribution of the dura, the pericranium, and the surrounding bone in adult versus infant animals. Plast Reconstr Surg 2003;112:515-27. doi:10.1097/01.PRS.0000070728.56716.51.

[74] Hobar PC, Masson JA, Wilson R, Zerwekh J. The importance of the dura in craniofacial surgery. Plast Reconstr Surg 1996;98:217-25. doi:10.1097/00006534-199608000-00003.

[75] Petrie C, Tholpady S, Ogle R, Botchwey E. Proliferative capacity and osteogenic potential of novel dura mater stem cells on poly-lactic-co-glycolic acid. J Biomed Mater Res - Part A 2008;85:61-71. doi:10.1002/jbm.a.31367. 